\title{
Guideline adherence for early breast cancer before and after introduction of the sentinel node biopsy
}

\author{
M Schaapveld ${ }^{*,}$, EGE de Vries ${ }^{2}$, R Otter ${ }^{2}$, J de Vries ${ }^{3}$, WV Dolsma ${ }^{4}$ and PHB Willemse ${ }^{5}$ \\ 'Comprehensive Cancer Center North-Netherlands, PO Box 330, 9700 AH Groningen, The Netherlands; '2Department of Medical Oncology, University \\ Medical Center Groningen, PO Box 30.00I, 9700 RB Groningen, The Netherlands; ${ }^{3}$ Department of Surgical Oncology, University Medical Center \\ Groningen, PO Box 30.00 I, 9700 RB Groningen, The Netherlands; ${ }^{4}$ Department of Radiotherapy, University Medical Center Groningen, PO Box 30.001 , \\ 9700 RB Groningen, The Netherlands; ${ }^{5}$ Department of Medical Oncology, University Medical Center Groningen, PO Box 30.00 I, 9700 RB Groningen, \\ The Netherlands
}

This population-based study aimed to analyse variations in surgical treatment and guideline compliance with respect to the application of radiotherapy and axillary lymph node dissection (ALND), for early breast cancer, before and after the sentinel node biopsy (SNB) introduction. The study included 13532 consecutive surgically treated stage I-IIIA breast cancer patients diagnosed in 1989-2002. Hospitals showed large variation in breast-conserving surgery (BCS) rates, ranging between 27 and $72 \%$ for TI and I4 and $42 \%$ for T2 tumours. In multivariate analysis marked inter-hospital and time-dependent variation in the BCS rate remained after correction for case-mix. The guideline adherence was markedly lower for elderly patients. In 25.2\% of the patients aged $\geqslant 75$ years either ALND or radiotherapy were omitted. The proportion of patients with no ALND after an SNB increased from 1.8\% in 1999 to $37.8 \%$ in 2002 . However, in 2002 also 12.2\% of the patients with a positive SNB did not have an ALND. Guideline compliance for BCS, with respect to radiotherapy and ALND, fell since the SNB introduction, from 96. 1\% before 2000 to 91.4\% in 2002 (P<0.00 I). Noncompliance may however reflect patient-tailored medicine, as for elderly patients with small, radically resected primary tumours. The considerable variation in BCS-rates is more consistent with variations in surgeon preferences than patient's choice.

British Journal of Cancer (2005) 93, 520-528. doi: I0.1038/sj.bjc.6602747 www.bjcancer.com

Published online 23 August 2005

(c) 2005 Cancer Research UK

Keywords: breast cancer; regional variation; breast-conserving surgery; guideline adherence; sentinel node biopsy

The establishment of a nationwide mammography breast-screening program for women aged 50-74 years has resulted in an increasing proportion of early breast cancers in the Netherlands during the 1990s (Nab et al, 1993; van Dijck et al, 2000). Over the last decade breast-conserving surgery (BCS) has become the standard treatment for early stage breast cancer, as firm data have shown that the outcome of BCS is comparable to the outcome after modified radical mastectomy (MRM) in terms of disease-specific survival (Veronesi et al, 1981; Fisher et al, 1985; EBCTG, 1995). Most breast cancer treatment guidelines state that the expected cosmetic outcome and patient preferences should guide the decision to perform BCS. Several studies, however, have indicated that surgical treatment for breast cancer may vary with the region or the hospital in which a patient is treated (Farrow et al, 1992; Nattinger et al, 1992; Voogd et al, 1994; Sainsbury et al, 1995; Scorpiglione et al, 1995; Bland et al, 1998; Guadagnoli et al, 1998b; Morrow et al, 2001). Although a large evidence base has been accumulated defining the most effective treatment strategies for early stage breast cancer, considerable treatment variability remains both between and within countries (Malin et al, 2002). Receiving less than appropriate care has been associated with an increased risk of recurrence and lower breast cancer-specific

*Correspondence: M Schaapveld; E-mail: m.schaapveld@ikn.nl Received I 4 February 2005; revised 20 July 2005; accepted 21 July 2005; published online 23 August 2005 survival (Lash et al, 2000). Regular performance measurements, using standardised clinical indicators, can play an important role in monitoring the patterns of care with regard to cancer treatment (Schneider et al, 2004).

This population-based study presents an overview of treatment patterns for early stage breast cancer in the Netherlands over the period 1989-2002. The aim of this study was to evaluate the variation in primary surgical treatment and the compliance with guidelines, with respect to the application of radiotherapy and axillary lymph node dissection, with emphasis on the effect of the sentinel node biopsy (SNB) introduction.

\section{PATIENTS AND METHODS}

\section{Patients}

All surgically treated stage I-IIIA (excluding TNM stages T3N0N2) breast cancer patients, diagnosed between January 1989 and January 2003 in the North-Netherlands and treated with either BCS or a MRM were eligible for inclusion. Patients with a prior invasive cancer, patients who received neo-adjuvant chemotherapy prior to surgery and patients with synchronous bilateral breast cancer, as defined by a contralateral breast cancer diagnosed within 3 months, were excluded. 


\section{Breast-screening}

A national breast-screening program, offering biennial mammography to women aged 50-69 years, was gradually implemented in the region since 1991. In 1997, all women in the target population had been invited at least once and since 1999 women aged 70-74 were also invited. All women received mammography in two directions for each breast: cranio-caudal and medio-latero-oblique. Two radiologists evaluated the mammograms by a double, independent reading. Women with a suspect mammogram were referred to the surgical department of one of the hospitals in the region for further evaluation.

\section{Data collection by the cancer registry}

Data were collected by the regional cancer registry of the Comprehensive Cancer Center North (CCCN), covering the Northern Netherlands, a mainly rural area with a population of about 2.1 million, served by 16 community hospitals, one university medical centre, four radiotherapy facilities and seven pathology laboratories. PALGA, the nationwide Dutch network and registry of histo- and cytopathology, regularly submits reports of newly diagnosed malignancies to the cancer registry. The national hospital discharge databank, which receives discharge diagnoses of admitted patients from all Dutch hospitals, completes case ascertainment. After notification, trained registry personnel collect data on diagnosis, staging, and treatment from the medical records, including pathology and surgery reports. All primary treatment received is coded in sequence of administration. Patients are staged according to the TNM system of the UICC (Hermanek and Sobin, 1992; Sobin and Wittekind, 1997).

\section{Guidelines}

The prevailing treatment guidelines for the study period are briefly outlined below. For patients with a tumour $<4 \mathrm{~cm}$, BCS with axillary lymph node dissection (ALND) was indicated, complemented with radiotherapy to the whole breast and a boost to the tumour excision area. The guidelines indicated that the surgical treatment should be based on the expected cosmetic outcome (tumour to breast ratio) and the patients' preferences. Alternatively, an MRM was performed. Loco-regional radiotherapy, consisting of parasternal, axillary, infra and supraclavicular nodal irradiation, was indicated in case of $>3$ positive axillary nodes or extranodal axillary growth. Parasternal irradiation was indicated for node-positive patients with a medially located tumour. Until 2000 ALND was indicated for all patients, after which a sufficient number of lymph nodes, at least 6 until 1998 and 10 thereafter, had to be pathologically examined. Since 2000 the guideline included the option of performing an SNB, for which a combined detection method was advised comprising peri- $/$ intratumoral radioactive tracer injection and lymphoscintigraphy one day before surgery and blue dye injection at induction of anaesthesia. When a positive SNB was detected an ALND was indicated. Surgeons with sufficient, documented, experience with the SNB procedure ( $>30$ SNB procedures with ALND as part of a learning curve) were allowed to omit ALND in patients with a negative SNB.

For the evaluation of guideline compliance, breast-conserving therapy was scored as 'appropriate' when it included an ALND and was complemented with radiotherapy; an MRM was considered in accordance with the guideline if complemented by an ALND. Omission of ALND was allowed after a negative SNB. An ALND with $>3$ positive nodes was considered an indication for regional radiotherapy, omission of radiotherapy was scored as inappropriate'. Omission of radiotherapy for node-positive medially located tumours was also scored as 'inappropriate' in the evaluation of guideline adherence.

\section{Statistical analysis}

The pathological tumour size was used to assess the choice of surgical treatment. In univariate analysis the $\chi^{2}$ test was used to examine the associations of categorical variables with the proportion of patients treated with BCS. The inter-hospital variation in the proportion of BCS was studied with Poisson regression analysis, adjusting for various patient and tumour characteristics. The rate of BCS was estimated against the regional average BCS rate as reference. Variables considered in the model were the hospital, patient age $(<40,40-49,50-59,60-69,70-79$ and $80+$ ), tumour localisation in the breast (central/nipple, medial, lateral, overlapping), tumour size $(\leqslant 1 \mathrm{~cm}$ or $\mathrm{T} 1 \mathrm{a} / 1 \mathrm{~b}$, $1-2 \mathrm{~cm}$ or T1c, $2.1-5 \mathrm{~cm}$ or T2), year of diagnosis (1989-1991, 1992-1994, 1995-1997, 1998-2000, 2001-2002), mode of detection (screen-detected $v s$ non-screen-detected) and distance from the nearest radiotherapy facility. Furthermore, first-order interactions of significant variables were tested (hospital with period of diagnosis, age at diagnosis and tumour size). Model fit was evaluated using the Pearson $\chi^{2}$ goodness-of-fit test statistic (McCullagh and Nelder, 1989). All reported $P$-values are two sided. A $P$-value $<0.05$ was considered significant.

\section{RESULTS}

\section{Type of surgery}

Between January 1989 and January 2003, 13532 consecutive patients were included. Table 1 shows some patient characteristics for patients receiving BCS. In total, $41.2 \%$ of the patients received BCS, $52.1 \%$ for a $\mathrm{T} 1$ and $26.5 \%$ for a T2 tumour. The proportion of patients treated with BCS varied markedly between the hospitals, ranging from 27.2 to $71.9 \%$ for $\mathrm{T} 1$ and from 13.5 to $42.3 \%$ for T2 tumours. Following a decrease between 1989 and 1995, the proportion receiving BCS gradually increased since 1996 for both T1 and T2 tumours (Figures 1 and 2). The initial decrease was most pronounced for patients $<50$ years, whereas for patients of $70+$ years the BCS rate remained more or less stable until 1996.

Screen-detected tumours were better candidates for BCS. The screen-detected T1 tumours were smaller than non-screendetected tumours. The proportion of tumours $\leqslant 1$ (T1A/B) and $1-2 \mathrm{~cm}(\mathrm{~T} 1 \mathrm{C})$ were 36.5 and $63.5 \%$ for screen-detected $v s 20.6$ and $79.4 \%$ for non-screen-detected tumours, respectively $(P<0.001)$. Furthermore, since the completion of the implementation phase of the screening program for women aged 50-69 years, the proportion of nonpalpable screen-detected tumours increased from 44.2 in 1997 to $57.3 \%$ in 2002 . Therefore, patients with screen-detected tumours actually were more likely to receive BCS (Table 2). Patients aged 50-69 and 70-74 years with a screendetected T1 tumour had a, respectively, 1.15 (95\% CI 1.08-1.22) and 1.81 (95\% CI $1.55-2.10)$ fold higher relative risk (RR) of receiving BCS. For the T2 tumours these figures were 1.37 (95\% CI $1.20-1.56)$ and 2.14 (95\% CI $1.48-3.09)$, respectively. The rate of BCS decreased with older age, with the notable exception of screen-detected T1 tumours. Only $23.1 \%$ of the patients $\geqslant 70$ years underwent BCS, compared to $49.8 \%$ of patients $<50$ years. Over the age of 80 years, BCS was applied in $17 \%$ of the patients with a $\mathrm{T} 1$ and $8.7 \%$ with a T2 tumour.

The distance from the municipality, where the patient lived, to the nearest radiotherapy facility correlated negatively with the proportion of patients receiving BCS, although the distance rarely exceeded $80 \mathrm{~km}$. The trend of a decreasing rate of BCS with increasing distance from a radiotherapy facility was seen for all age groups, with the exception of patients $\geqslant 70$ years with T2 tumours, and persisted over time. However, stratified by hospital, the association between distance from a radiotherapy facility and BCS disappeared, indicating that hospital could also explain the observed association. 
Table I Characteristics of all patients and those receiving breastconserving surgery (BCS)

\begin{tabular}{|c|c|c|c|}
\hline & \multirow{2}{*}{$\begin{array}{c}\text { All patients } \\
\text { Number }\end{array}$} & \multicolumn{2}{|c|}{ Patients receiving $\mathrm{BCS}$} \\
\hline & & Number & $\%$ \\
\hline \multicolumn{4}{|l|}{ Tumour location } \\
\hline Central & 878 & 239 & 27.2 \\
\hline Medial & 2788 & 1260 & 45.2 \\
\hline Lateral & 6708 & 2950 & 44.0 \\
\hline Overlapping & 3158 & 1128 & 35.7 \\
\hline \multicolumn{4}{|l|}{ Tumour size } \\
\hline $\mathrm{T} \mid \mathrm{A} / \mathrm{B}$ & 2023 & 1178 & 58.2 \\
\hline $\mathrm{TIC}$ & 5766 & 2878 & 49.9 \\
\hline $\mathrm{T} 2$ & 5743 & $|52|$ & 26.5 \\
\hline \multicolumn{4}{|l|}{ Age (years) } \\
\hline$<50$ & 3473 & 1718 & 49.5 \\
\hline $50-69$ & 6645 & 3079 & 46.3 \\
\hline $70-74$ & 1450 & 478 & 33.0 \\
\hline $75+$ & 1964 & 302 & 15.4 \\
\hline \multicolumn{4}{|c|}{ Total number of patients treated per hospital } \\
\hline Average & 712 & 293 & 41.2 \\
\hline Range & $222-2231$ & $63-793$ & $21.5-60.8$ \\
\hline \multicolumn{4}{|c|}{ Distance from radiotherapy department $(\mathrm{km})$} \\
\hline $0-9.9$ & 2439 & |||| & 45.6 \\
\hline $10-24.9$ & 2681 & 1149 & 42.9 \\
\hline $25-44.9$ & 5470 & 2266 & 41.4 \\
\hline $45+$ & 2896 & 1025 & 35.4 \\
\hline \multicolumn{4}{|l|}{ Year of diagnosis } \\
\hline $1989-199 \mid$ & 2145 & 769 & 35.9 \\
\hline $1992-1994$ & 2667 & 897 & 33.6 \\
\hline $1995-1997$ & 2951 & 1049 & 35.5 \\
\hline $1998-2000$ & 3265 & $|53|$ & 46.9 \\
\hline $2001-2002$ & 2504 & $133 \mid$ & 53.2 \\
\hline \multicolumn{4}{|l|}{ Mode of detection } \\
\hline Screen detected & 3327 & 1830 & 55.0 \\
\hline Non-screen detected & 10205 & 3747 & 36.7 \\
\hline \multicolumn{4}{|l|}{ Histology } \\
\hline Ductal carcinoma & | 484 & 4943 & 43.0 \\
\hline Lobular carcinoma $^{a}$ & 1429 & 430 & 30.1 \\
\hline Other $^{\mathrm{b}}$ & 617 & 203 & 32.9 \\
\hline
\end{tabular}

\section{Multivariate analysis for type of surgery}

In a Poisson regression analysis, older age, larger tumour size, lobular histology, central location or overlapping quadrants and a non-screen-detected cancer were all independently associated with a decreased BCS rate. Compared to patients with T1 tumours a patient with a T2 tumour had a RR of 0.58 (95\% CI $0.54-0.63)$ of receiving BCS. Compared to patients $<50$ years, the RR of receiving BCS were 0.98 (95\% CI $0.88-1.10), 0.87$ (95\% CI $0.77-$ 0.97), 0.74 (95\% CI $0.65-0.83), 0.52$ (95\% CI $0.46-0.60)$ and 0.26 $(95 \%$ CI $0.21-0.32)$ for the $50-59,60-69,70-74,74-79$ and $80+$ year age groups, respectively. A lobular histology decreased the rate of BCS by $26 \%$ (RR $0.74,95 \%$ CI $0.66-0.82$ ) and central tumour location or a tumour in overlapping quadrants decreased the rate of BCS with $18 \%$ (RR $0.82,95 \%$ CI $0.75-0.89$ ) and $31 \%$ (RR $0.69,95 \%$ CI $0.60-0.80$ ), respectively, compared to lateral or medial tumours. A non-screen-detected tumour was associated with a decreased BCS rate (RR $0.83,95 \%$ CI $0.77-0.89$ ). Even after correction for case mix, marked inter-hospital variation in the BCS rate remained. Following tumour size and patient age, the individual hospital was the most important variable predicting the likelihood of BCS (Figure 3). A strong effect of modification was found by year of diagnosis, the effect of time varying significantly between the hospitals (Table 3 ).

\section{Adjuvant radiotherapy after BCS}

Of the 5577 patients who received BCS as definitive surgical therapy, $96.5 \%$ received radiotherapy. Withholding radiotherapy after BCS was associated with age. Whereas $97.7 \%$ of the patients $<70$ years received radiotherapy, these figures were 95.8, 90.9 and $57.4 \%$ for patients aged $70-74$ years, $75-79$ and $\geqslant 80$ years, respectively $(P<0.001)$. Furthermore, the proportion of patients not receiving radiotherapy after BCS differed between the areas covered by the three regional radiotherapy facilities $(5.0,3.5$ and $1.7 \%$, respectively, $P<0.001$ ). Differences in treatment policy for the older patients partly explained this finding, as 63.2, 67.6 and $92.6 \%$ of the patients aged $\geqslant 75$ years received radiotherapy after BCS in the three radiotherapy facilities, respectively $(P<0.001)$. Over time, the proportion of patients receiving radiotherapy following BCS remained stable, but the number of patients treated increased 2.7-fold between 1989 and 2002 .

\section{Radiotherapy after MRM}

Of the 7955 patients treated with an MRM, 21.6\% subsequently received radiotherapy. Of these patients, $70.9 \%$ either had extensive lymph node involvement or a node-positive medial tumour. Of the patients who did not receive radiotherapy, $10.4 \%$ had these radiotherapy indications. Older patients were less likely to receive radiotherapy when indicated. Of the patients with a radiotherapy indication aged $\geqslant 75$ years, $52.9 \%$ actually received radiotherapy compared to $69.2 \%$ of the patients $<75$ years $(P<0.001)$. Although the proportion of patients treated with radiotherapy differed slightly between the three radiotherapy facilities, after adjusting for radiotherapy indication this difference disappeared $(P=0.254)$. Both the proportion and number of patients receiving radiotherapy after MRM remained stable over time.

\section{Axillary lymph node dissection and SNB}

Before 2000 , only $1.8 \%$ of the patients did not have an ALND $(2.1 \%$ with a T1 and $1.4 \%$ with a T2 tumour). The proportion of patients without ALND increased from $1.0 \%$ in 1989 to $2.4 \%$ in 1998 and increased markedly with older age in this period, totalling $7.9 \%$ among patients aged $\geqslant 80$ years. The SNB was introduced at the end of 1998 and during 1998-2000 most patients received ALND after an SNB, as part of the surgeon's learning curve. Since 2000 the proportion of patients receiving an SNB increased. In 2002 only $34.8 \%$ of the patients still underwent an ALND without a prior SNB (Figure 4). The proportion of patients who underwent an SNB without a subsequent ALND increased steadily from 1.8\% in 1999 to $37.8 \%$ in 2002 . The proportion of patients without ALND after a positive SNB increased markedly in 2002 to $12.2 \%$.

\section{Adherence to the guidelines for primary treatment}

Table 4 illustrates the guideline adherence for early stage breast cancer. Following BCSn $95.0 \%$ of the patients underwent an ALND and subsequently received radiotherapy. The guideline adherence for breast-conserving therapy decreased following the SNB introduction, from $95.6 \%$ in 1999 to $91.3 \%$ in 2002 compared to, on average, $96.8 \%$ in the previous years $(P<0.001)$. During $2001-$ $2002,3.1 \%$ of the patients treated with BCS did not have radiotherapy, $4.2 \%$ did not have ALND and in $1.3 \%$ both radiotherapy and ALND were omitted. Of the patients with no 


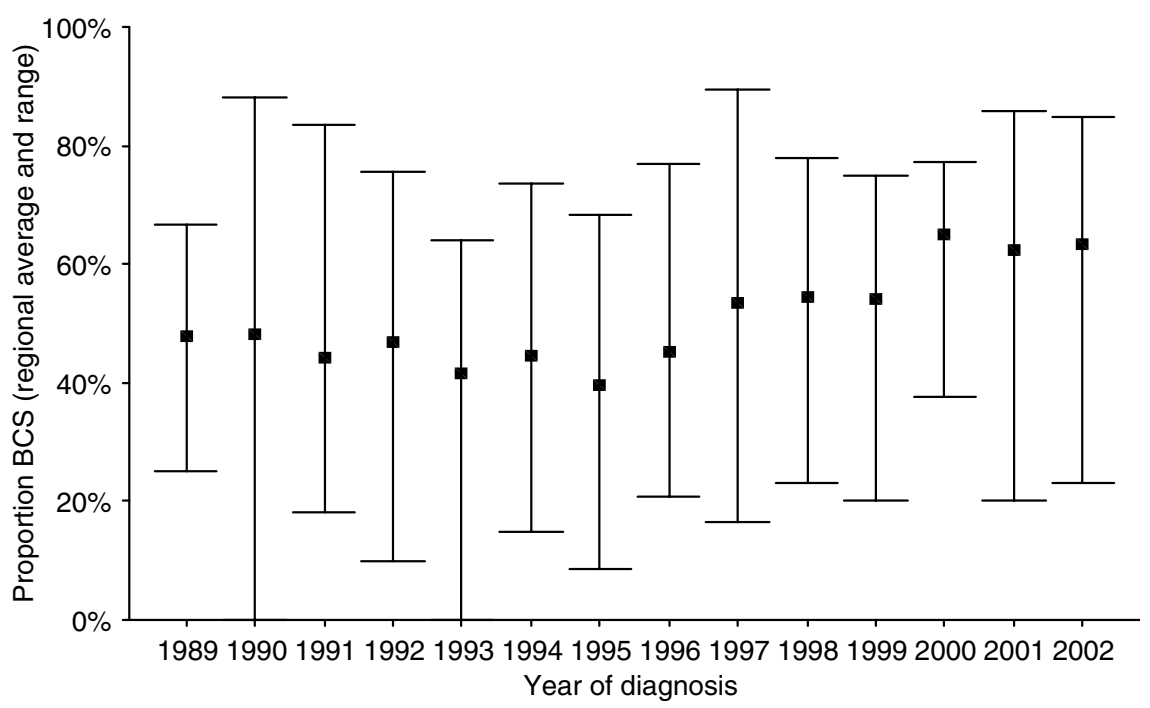

Figure I Inter-hospital variation in the proportion of TI tumours treated with breast-conserving surgery (BCS) by year of diagnosis. The square represents the regional average; the bars represent the range between all hospitals.

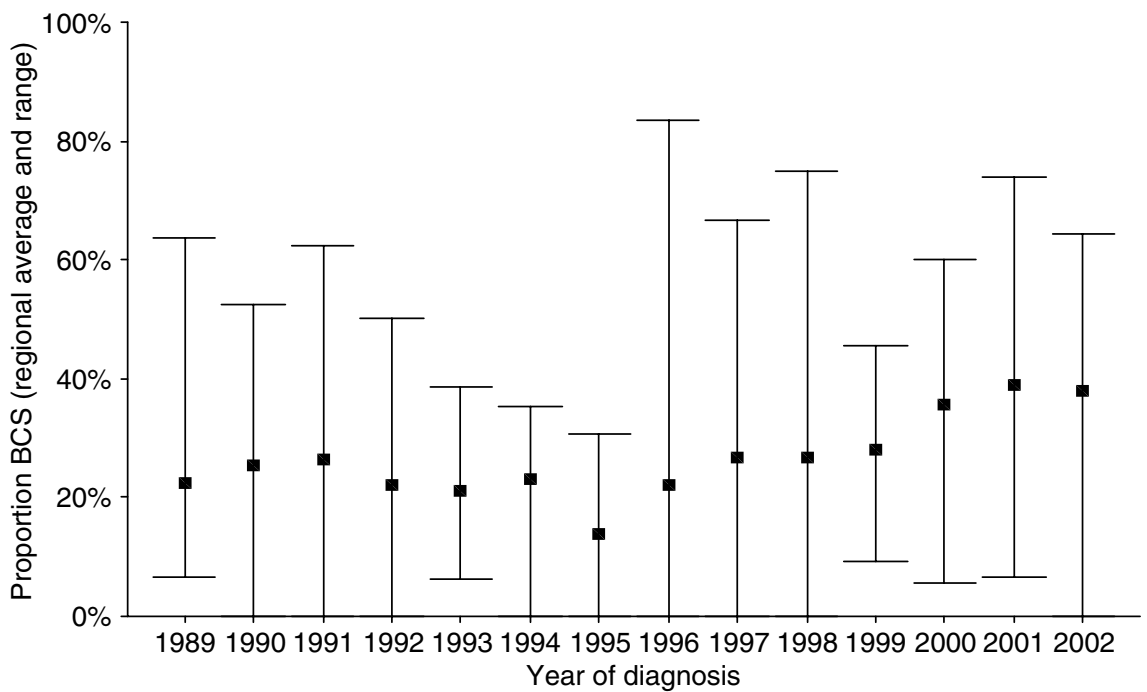

Figure 2 Inter-hospital variations in the proportion of T2 tumours treated with breast-conserving surgery (BCS) by year of diagnosis. The square represents the regional average; the bars represent the range between all hospitals.

Table 2 Breast-conserving surgery (BCS) rate according to the mode of detection, age and tumour size

\begin{tabular}{|c|c|c|c|c|c|}
\hline \multirow[b]{2}{*}{ Mode of detection } & \multirow[b]{2}{*}{ Age (years) } & \multicolumn{2}{|c|}{ TI } & \multicolumn{2}{|c|}{ T2 } \\
\hline & & $\begin{array}{c}\text { BCS } \\
\%\end{array}$ & $\begin{array}{c}\text { Total } \\
\mathbf{N}\end{array}$ & $\begin{array}{c}\text { BCS } \\
\%\end{array}$ & $\begin{array}{c}\text { Total } \\
\mathbf{N}\end{array}$ \\
\hline Non-screen detected & $\begin{array}{l}<50 \\
50-69 \\
70-74 \\
75+ \\
\text { Total }\end{array}$ & $\begin{array}{l}60.4 \\
52.0 \\
33.8 \\
19.5 \\
48.1\end{array}$ & $\begin{array}{r}1876 \\
1969 \\
488 \\
826 \\
5159\end{array}$ & $\begin{array}{l}36.0 \\
27.5 \\
14.9 \\
10.5 \\
25.0\end{array}$ & $\begin{array}{r}1535 \\
1874 \\
545 \\
1092 \\
5046\end{array}$ \\
\hline Screen detected & $\begin{array}{l}<50 \\
50-69 \\
70-74 \\
75+ \\
\text { Total }\end{array}$ & $\begin{array}{l}58.0 \\
59.5 \\
61.2 \\
68.6 \\
59.8\end{array}$ & $\begin{array}{r}50 \\
2210 \\
335 \\
35 \\
2630\end{array}$ & $\begin{array}{l}25.0 \\
38.0 \\
32.9 \\
18.2 \\
36.9\end{array}$ & $\begin{array}{r}12 \\
592 \\
82 \\
11 \\
697\end{array}$ \\
\hline
\end{tabular}

ALND, 54.8\% had a positive SNB. The compliance with breastconserving therapy guidelines decreased with older patient age $(P<0.001)$. During $1989-2002,25.2 \%$ of the patients aged $\geqslant 75$ years received 'inappropriate' breast-conserving therapy (omission of radiotherapy, ALND or both). Guideline compliance for breastconserving therapy was lower following the SNB introduction in all age groups.

Guideline compliance for patients treated with an MRM averaged $90.6 \%$, predominantly due to omission of radiotherapy for patients with (extensive) lymph node involvement. Of the 1642 patients with $>3$ positive (or fixed nodes/extracapsular tumour extension) axillary nodes, $39.4 \%$ did not receive radiotherapy although it was indicated. When indicated, radiotherapy was more frequently omitted in patients $<50$ years or $\geqslant 75$ years compared to patients aged 50-74 years. In $1.8 \%$ of the patients an ALND was incorrectly omitted; this proportion increased with older age and in the most recent years. The guideline compliance was lowest for patients aged $\geqslant 75$ years due to relatively frequent omission of either radiotherapy or ALND. 
Table 3 Results of multivariate Poisson regression analysis for variation in the rate of breast-conserving surgery (BCS) and estimated rate ratios (RR) of BCS by hospital for each period of diagnosis (with 1989-1991 as reference)

\begin{tabular}{|c|c|c|c|c|c|c|c|}
\hline & & & \multicolumn{5}{|c|}{ Time trend for BCS } \\
\hline & & & $|989-| 99 \mid$ & | $992-1994$ & | $995-1997$ & $1998-2000$ & $2001-2002$ \\
\hline & $\mathbf{R R}^{\mathbf{a}}$ & $95 \% \mathrm{Cl}$ & $\mathbf{R R}$ & $\mathbf{R R}$ & $\mathbf{R R}$ & $\mathbf{R R}$ & $\mathbf{R R}$ \\
\hline \multicolumn{8}{|l|}{ Hospital } \\
\hline Hospital A & 1.89 & $1.14-3.12$ & 1.00 & 0.72 & 0.83 & 0.99 & 1.14 \\
\hline Hospital B & 1.87 & $1.18-2.95$ & 1.00 & 0.85 & 0.84 & 0.97 & 0.98 \\
\hline Hospital C & 1.93 & $1.06-3.50$ & 1.00 & 0.40 & 0.88 & 0.92 & 1.01 \\
\hline Hospital D & 1.38 & $0.80-2.37$ & 1.00 & 1.09 & 0.98 & 1.11 & $|.5|$ \\
\hline Hospital E & 1.68 & $1.02-2.76$ & 1.00 & 0.83 & 0.81 & 0.78 & 0.95 \\
\hline Hospital F & 1.30 & $0.79-2.12$ & 1.00 & 0.97 & 1.03 & 1.22 & 1.43 \\
\hline Hospital G & 1.66 & $0.95-2.89$ & 1.00 & 0.78 & 1.02 & 0.62 & 0.74 \\
\hline Hospital H & 0.96 & $0.63-1.46$ & 1.00 & 1.15 & 0.95 & 1.64 & 1.58 \\
\hline Hospital I & 0.91 & $0.51-1.61$ & 1.00 & 0.92 & 0.95 & 1.69 & 1.88 \\
\hline Hospital J & 1.04 & $0.61-1.75$ & 1.00 & 0.81 & 0.73 & 1.39 & 1.66 \\
\hline Hospital K & 1.26 & $0.68-2.31$ & 1.00 & 0.77 & 0.77 & 0.85 & 0.87 \\
\hline Hospital L & 0.61 & $0.34-1.10$ & 1.00 & 1.63 & 1.55 & 1.86 & 2.30 \\
\hline Hospital M & 0.71 & $0.37-1.36$ & 1.00 & 1.05 & 0.81 & 1.45 & 2.54 \\
\hline Hospital N & 0.98 & $0.61-1.56$ & 1.00 & 0.79 & 0.67 & 1.36 & 1.38 \\
\hline Hospital $\bigcirc$ & 0.53 & $0.25-1.14$ & 1.00 & 1.10 & 1.81 & 2.33 & 2.94 \\
\hline Hospital P & 1.03 & $0.57-1.86$ & 1.00 & 1.00 & 0.94 & 1.31 & 0.58 \\
\hline Hospital Q & 1.63 & $0.80-3.32$ & 1.00 & 0.52 & 0.52 & 0.56 & 0.71 \\
\hline Hospital R & 0.61 & $0.31-1.17$ & 1.00 & 1.23 & 0.88 & 2.19 & 1.46 \\
\hline Hospital S & 0.58 & $0.26-1.27$ & 1.00 & 1.00 & 1.02 & 1.38 & 1.06 \\
\hline
\end{tabular}

${ }^{a}$ Relative risk of BCS for the period 1989-1991 vs the regional average BCS rate, adjusted for age, tumour size, period of diagnosis, histology, location and mode of detection 95\% Cl: 95\% confidence interval for RR.

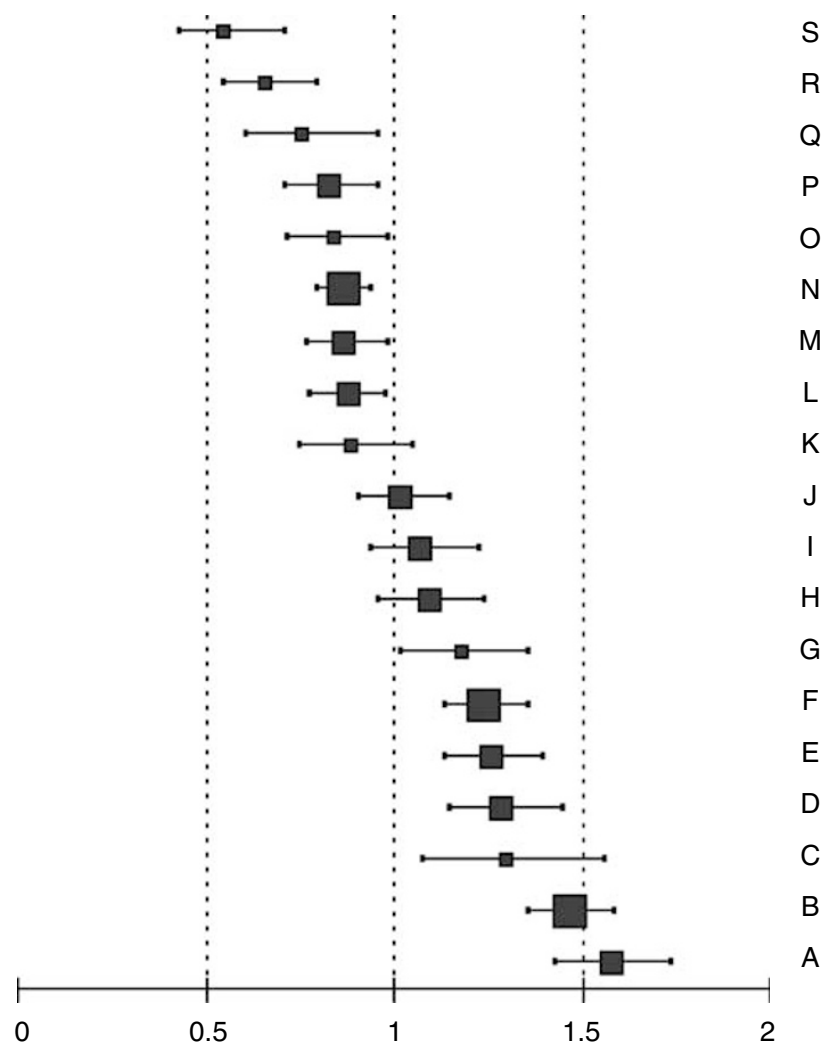

Figure 3 Estimated rate ratios with 95\% confidence intervals for breastconserving surgery (BCS) by hospital (denoted by the letters $A-S$ ) vs the regional average BCS rate (reference is 1.0) in the Comprehensive Cancer Center North region 1989-2002 (hospital with $<500$ patients $-\boldsymbol{E}$, with 500-999 patients $\square$ and with $\geqslant 1000$ patients $\square$ diagnosed between 1989 and 2002)

\section{DISCUSSION}

In this population-based study, large inter-hospital variation in BCS was observed, which persisted after adjustment for case-mix. Following tumour size and age, the individual hospital was the most important variable predicting the likelihood of receiving BCS. Generally, hospitals, which scored far under or above the regional average, did so during the whole study period. The time trend for BCS varied significantly between the hospitals. Besides changes in doctors and patients attitudes towards BCS, changes in the surgical staff are a possible explanation for this observation. It is very likely that the observed inter-hospital variation in BCS reflects surgeon preference more than patient preference.

A study evaluating the effect of an interactive treatment decision aid in a Dutch patient population $(N=172)$ showed that the patients' perception of her physicians' treatment preference was an important factor in decision making (Molenaar et al, 2004). In a population-based study, Katz et al found that patients who did not feel they had had a choice between surgical options perceived less satisfaction with the decision-making process (Katz et al, 2001). Informed decision making by the patient does not necessarily imply that a patient will choose BCS, however. A survey among 1489 patients in the Detroit and Los Angeles metropolitan area, performed shortly after surgery, found that patients who felt involved in the decision making were actually more inclined to accept MRM, whereas patients who underwent BCS felt more frequently that their surgeon made the treatment decision (Katz et al, 2004). In a study in Western Australia, women who received BCS also reported a more important role of the surgeon's preference in their decision-making than those who had had an MRM (Mastaglia and Kristjanson, 2001). A study, evaluating a decision board to help surgeons inform breast cancer patients about their treatment options, also had interesting effects. While the surgeons stated that the instrument improved communication and facilitated shared decision-making, the rate of BCS decreased after its introduction (Whelan et al, 1999). It remains therefore 
Type of surgery and guideline adherence in breast cancer

M Schaapveld et al

Table 4 Guideline adherence for axillary lymph node dissection (ALND) and radiotherapy (RT) in breast cancer treatment, by type of surgery, age and period of diagnosis

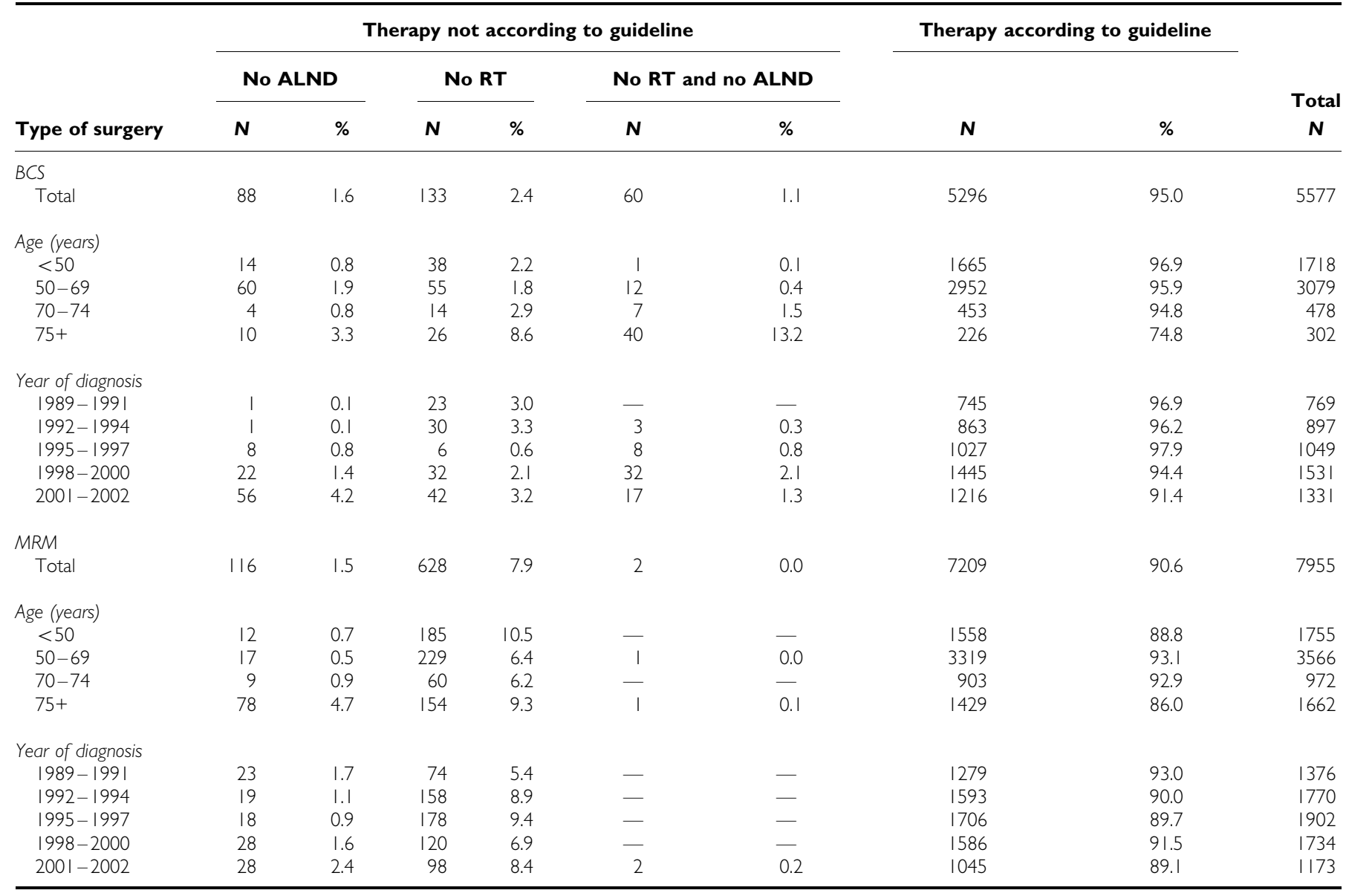

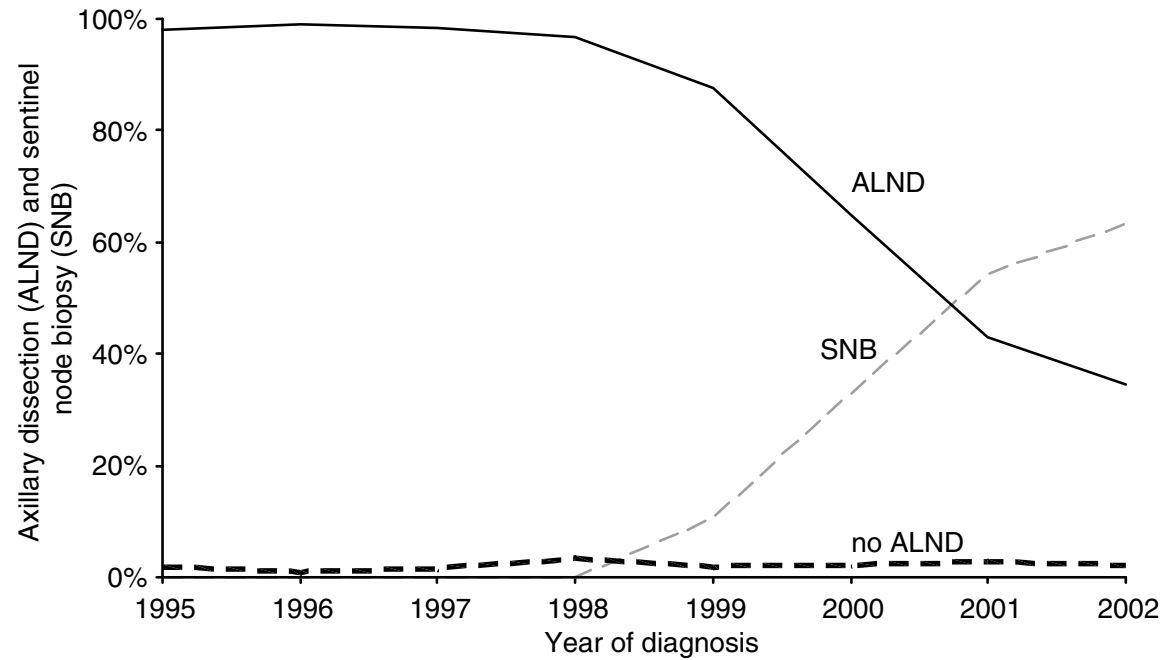

Figure 4 Time trend for sentinel lymph node biopsy and axillary lymph node dissection for breast cancer in the Comprehensive Cancer Center North region 1995-2002.

questionable whether the rate of BCS can be used indiscriminately as a standard for good quality of care. Nevertheless, several studies have shown that various quality of life indicators may differ between patients treated with BCS or MRM (Ganz et al, 1992; Pozo et al, 1992; Poulsen et al, 1997; Arora et al, 2001; Janni et al, 2001; Engel et al, 2004). Recently, it was shown that patients who underwent an MRM scored worse on body image, sexual functioning and lifestyle disruption compared to patient treated 
with BCS, while these scores did not improve over time in either patient group (Engel et al, 2004). Previous studies also reported that especially younger patients scored particularly worse on body image after an MRM than patients treated with BCS (Ganz et al, 1992; Arora et al, 2001).

The proportion of patients treated with BCS in our population was comparable to that in the USA, according to the data from the SEER registry (Lazovich et al, 1999). In the Southeast-Netherlands, $67 \%$ of stage I and $43 \%$ of stage II breast cancers received BCS in 1990-1991 (Voogd et al, 1994), proportions which were attained only in some hospitals in our region.

A temporary decrease in the BCS rate was observed during the mid-1990s. We can only speculate about the cause. The decrease manifested following publications showing an increased local recurrence risk after BCS for patients with larger tumours, tumours with an extensive in situ component and for patients younger than 40 years (Delouche et al, 1987; Bartelink et al, 1988; Boyages et al, 1990; Lichter et al, 1992). Also, in this period the breast-screening program rapidly expanded, which may have resulted in logistic problems in hospitals and radiotherapy facilities. The number of patients diagnosed with early stage breast cancer increased almost 40\% in the period 1995-1997 compared to $1989-1991$. On the other hand, in our study actually patients with screen-detected, early stage breast cancer were more likely to receive BCS, even after adjusting for tumour size. A study in the Southeast-Netherlands also found a higher likelihood of BCS for patients with screen-detected cancers, although this study did not correct for differences in tumour size between screen-detected and non-screen-detected cancers (Ernst et al, 2001).

Primary therapy generally was given in accordance with the guidelines. In all, $95 \%$ of the patients treated with BCS underwent ALND and received radiotherapy. Most patients (98.5\%) had an ALND as part of an MRM. These results compare favourably with studies from the USA (Guadagnoli et al, 1998b; Lazovich et al, 1999; Nattinger et al, 2000; Morrow et al, 2001). Nattinger et al observed an increasing trend of inappropriate treatment of early stage breast cancer in the SEER database, mainly due to an increased proportion of patients receiving breast-conserving therapy and the higher likelihood of inappropriate breastconserving therapy (omission of ALND, radiotherapy or both) compared to MRM; $19 \%$ of the patients treated in 1995 received incomplete treatment (Nattinger et al, 2000). In our population, the proportion of patients treated in accordance with the guideline fell since 1998, following the introduction of the SNB, frequently due to omission of ALND. Several studies have reported lower use of ALND and postoperative radiotherapy in the elderly patient (Voogd et al, 1994; Guadagnoli et al, 1998a; Hebert-Croteau et al, 1999; Edge et al, 2002; Giordano et al, 2005). The benefit of ALND for elderly patients has been seriously questioned in the literature (Wazer et al, 1994; Newlin et al, 2002; Martelli et al, 2003) and surgeons may be reluctant to perform an additional ALND (following BCS or SNB) in elderly patients as they frequently suffer from comorbidity. Over the years 2001-2002, in our study $50 \%$ of the patients who did not have an ALND had a tumour positive SNB; most of these patients were over 50 years of age. One could argue that the outcome of ALND in this group of patients would not often change the projected adjuvant treatment and as such may represent appropriate patient-tailored medical practice. In our population radiotherapy, as part of BCS, was omitted in $22 \%$ of the patients aged $\geqslant 75$ years. A recent CALGB-study, comparing lumpectomy plus tamoxifen with and without radiation in women with clinical stage I breast cancer aged $\geqslant 70$ years, found only a small nonsignificant excess risk of local recurrence in the nonirradiated group and no differences in distant metastases risk or survival (Hughes et al, 2004). Another recent study examined local recurrences rates among patients who refused radiotherapy or had medical contraindications and found low local recurrence rates among elderly patients with small, lower grade tumours operated with adequate resection margins (Lee et al, 2004). Although inappropriate according to the guideline, omitting radiotherapy after BCS in the very elderly appears to be reasonable medical practice for elderly patients with small, adequately resected tumours.

The prevailing guideline for elective nodal irradiation was largely based on the extent of nodal involvement during the study period. A relatively recent meta-analysis showed that postoperative locoregional radiotherapy resulted in a survival advantage for high-risk patients (Whelan et al, 2000). Other studies have shown that even after an adequate axillary dissection and adjuvant systemic therapy, a high risk of locoregional recurrence remained in patients with a high number of involved nodes when these patients did not receive postoperative radiotherapy (Ragaz et al, 1997; Recht et al, 1999). Although it is as yet not completely clear which patients do need locoregional radiotherapy, in the Netherlands the current guidelines advise to give axillary and supraclavicular radiotherapy in case of $>3$ positive axillary lymph nodes or a positive apical node. In our study, $39 \%$ of the patients treated with an MRM for whom radiotherapy was indicated according to this guideline actually were not irradiated. Comorbidity and older age have previously been associated with decreased use of locoregional radiotherapy (Ballard-Barbash et al, 1996; Hebert-Croteau et al, 1999; Morrow et al, 2001). There is a need for guidelines, which better address treatment issues in the elderly breast cancer patient, especially as the elderly comprise a growing proportion of our patient populations.

This study provides an evaluation of current treatment patterns for breast cancer. To ensure that these results would improve the quality of care, the data were presented to delegations from all regional hospitals, including delegates from the surgical staff, during three invitational conferences in the first half of 2005. Unit names were not removed in these presentations. The variation in BCS has been discussed repeatedly within the Comprehensive Cancer Center North (CCCN) breast cancer working group and more recently within the Surgical Oncological Network North Netherlands, a CCCN working group comprising surgeons from all hospitals in the CCCN region. As a result of these discussions, the CCCN cancer registry provides since 2003, among other data, stage and age specific rates of BCS for each hospital in the CCCN region. These data are regularly discussed within the Surgical Oncological Network North Netherlands, during which the results of individual units are opened to all other hospitals and are compared to the regional average and that of other centres. Largely as a result of these discussions we have seen a marked increase in the proportion of patients treated with BCS.

\section{REFERENCES}

Arora NK, Gustafson DH, Hawkins RP, McTavish F, Cella DF, Pingree S, Mendenhall JH, Mahvi DM (2001) Impact of surgery and chemotherapy on the quality of life of younger women with breast carcinoma: a prospective study. Cancer 92: $1288-1298$
Ballard-Barbash R, Potosky AL, Harlan LC, Nayfield SG, Kessler LG (1996) Factors associated with surgical and radiation therapy for early stage breast cancer in older women. J Natl Cancer Inst 88: $716-726$ 
Bartelink H, Borger JH, van Dongen JA, Peterse JL (1988) The impact of tumor size and histology on local control after breast-conserving therapy. Radiother Oncol 11: 297-303

Bland KI, Menck HR, Scott-Conner CE, Morrow M, Winchester DJ, Winchester DP (1998) The National Cancer Data Base 10-year survey of breast carcinoma treatment at hospitals in the United States. Cancer 83: $1262-1273$

Boyages J, Recht A, Connolly JL, Schnitt SJ, Gelman R, Kooy H, Love S, Osteen RT, Cady B, Silver B, Harris JR (1990) Early breast cancer: predictors of breast recurrence for patients treated with conservative surgery and radiation therapy. Radiother Oncol 19: 29-41

Delouche G, Bachelot F, Premont M, Kurtz JM (1987) Conservation treatment of early breast cancer: long term results and complications. Int J Radiat Oncol Biol Phys 13: 29-34

van Dijck JAAM, Hendriks JHCL, Holland R, Schouten LJ, Verbeel ALM (2000) Change in stage distribution of breast cancer since the implementation of nation-wide screening; investigation in the Netherlands over the period 1989-1995. Ned Tijdschr Geneeskd 144: 1119-1124

Early Breast Cancer Trialists' Collaborative Group (1995) Effects of radiotherapy and surgery in early breast cancer. An overview of randomized trials. $N$ Engl J Med 33: $1444-1455$

Edge SB, Gold K, Berg CD, Meropol NJ, Tsangaris TN, Gray L, Petersen Jr BM, Hwang YT, Mandelblatt JS, Outcomes and Preferences for Treatment in Older Women Nationwide Study Research Team (2002) Patient and provider characteristics that affect the use of axillary dissection in older women with stage I- II breast carcinoma. Cancer 94: $2534-2541$

Engel J, Kerr J, Schlesinger-Raab A, Sauer H, Holzel D (2004) Quality of life following breast-conserving therapy or mastectomy: results of a 5-year prospective study. Breast J 10: 223-231

Ernst MF, Voogd AC, Coebergh JWW, Repelaer van Driel OJ, Roukema JA (2001) The introduction of mammographical screening has had little impact on the trend in breast-conserving surgery: a population-based study in South-east Netherlands. Eur J Cancer 37: 2435-2440

Farrow D, Hunt WC, Samet JM (1992) Geographic variation in the treatment of localized breast cancer. N Engl J Med 326: 1097-1101

Fisher B, Bauer M, Margolese R, Poisson R, Pilch Y, Redmond C, Fisher E, Wolmark N, Deutsch M, Montague E (1985) Five-year results of a randomized clinical trial comparing total mastectomy and segmental mastectomy with or without radiation in the treatment of breast cancer. $N$ Engl J Med 312: 665-673

Ganz PA, Schag AC, Lee JJ, Polinsky ML, Tan SJ (1992) Breast conservation versus mastectomy. Is there a difference in psychological adjustment or quality of life in the year after surgery? Cancer 69: 1729-1738

Giordano SH, Hortobagyi GN, Kau SC, Theriault RL, Bondy ML (2005) Breast cancer treatment guidelines in older women. J Clin Oncol 23: $783-791$

Guadagnoli E, Shapiro CL, Weeks JC, Gurwitz JH, Borbas C, Soumerai SB (1998a) The quality of care for treatment of early stage breast carcinoma: is it consistent with national guidelines? Cancer 83: 302-309

Guadagnoli E, Weeks JC, Shapiro CL, Gurwitz JH, Borbas C, Soumerai SP (1998b) Use of breast-conserving surgery for treatment of stage I and stage II breast cancer. J Clin Oncol 16: 101-106

Hebert-Croteau N, Brisson J, Latreille J, Blanchette C, Deschenes L (1999) Compliance with consensus recommendations for the treatment of early stage breast carcinoma in elderly women. Cancer 85: $1104-1113$

Hermanek P, Sobin LH (eds) (1992) International Union Against Cancer (UICC): TNM Classification of Malignant Tumors 4th edn, 2nd revision. Berlin, Heidelberg, New York, London, Paris, Tokyo, Hongkong, Barcelona, Budapest: Springer-Verlag

Hughes KS, Schnaper LA, Berry D, Cirrincione C, McCormick B, Shank B, Wheeler J, Champion LA, Smith TJ, Smith BL, Shapiro C, Muss HB, Winer E, Hudis C, Wood W, Sugarbaker D, Henderson IC, Norton L, Cancer and Leukemia Group B; Radiation Therapy Oncology Group; Eastern Cooperative Oncology Group (2004) Lumpectomy plus tamoxifen with or without irradiation in women 70 years of age or older with early breast cancer. N Engl J Med 351: 971-977

Janni W, Rjosk D, Dimpfl TH, Haertl K, Strobl B, Hepp F, Hanke A, Bergauer F, Sommer H (2001) Quality of life influenced by primary surgical treatment for stage I-III breast cancer-long-term follow-up of a matched-pair analysis. Ann Surg Oncol 8: $542-548$

Katz SJ, Lantz PM, Janz NK, Fagerlin A, Salem B, Lakhani I, Morrow M (2004) Shared decision-making and surgical treatment for breast cancer. J Clin Oncol 22: 16 (suppl; abstr 556)
Katz SJ, Lantz PM, Zemencuk JK (2001) Correlates of surgical treatment type for women with noninvasive and invasive breast cancer. $J$ Womens Health Gender Based Med 10: 659-670

Lash TL, Silliman RA, Guadagnoli E, Mor V (2000) The effect of less than definitive care on breast carcinoma recurrence and mortality. Cancer 89: $1739-1747$

Lazovich D, Solomon CC, Thomas DB, Moe RE (1999) Breast Conservation Treatment in the United States following the 1990 National Institute of Health consensus development conference on the treatment of patients with early stage invasive breast carcinoma. Cancer 86: 629-637

Lee SH, Chung MA, Chelmow D, Cady B (2004) Avoidance of adjuvant radiotherapy in selected patients with invasive breast cancer. Ann Surg Oncol 11: 316-321

Lichter AS, Lippman ME, Danforth Jr DN, d'Angelo T, Steinberg SM, deMoss E, MacDonald HD, Reichert CM, Merino M, Swain SM, Cowan K, Gerber LH, Bader JL, Findlay PA, Schain W, Gorreli CR, Straus K, Rosenberg SA, Glatstein E (1992) Mastectomy versus breast-conserving therapy in the treatment of stage I and II carcinoma of the breast: a randomized trial at the National Cancer Institute. J Clin Oncol 10: 976-983

Malin JL, Schuster MA, Kahn KA, Brook RH (2002) Quality of breast cancer care: what do we know? J Clin Oncol 20: $4381-4393$

Martelli G, Miceli R, De Palo G, Coradini D, Salvadori B, Zucali R, Galante E, Marubini E (2003) Is axillary lymph node dissection necessary in elderly patients with breast carcinoma who have a clinically uninvolved axilla? Cancer 97: 1156-1163

Mastaglia B, Kristjanson LJ (2001) Factors influencing women's decisions for choice of surgery for Stage I and Stage II breast cancer in Western Australia. J Adv Nurs 35: 836-847

McCullagh P, Nelder JA (1989) Generalized Linear Models 2nd edn London: Chapman \& Hall

Molenaar S, Oort F, Sprangers M, Rutgers E, Luiten E, Mulder J, De Haes H (2004) Predictors of patients' choices for breast-conserving therapy or mastectomy: a prospective study. Br J Cancer 90: 2123-2130

Morrow M, White J, Moughan J, Owen J, Pajack T, Sylvester J, Wilson JF, Winchester D (2001) Factors predicting the use of breast-conserving therapy in stage I and II breast carcinoma. J Clin Oncol 19: 2254-2262

Nab HW, Voogd AC, Crommelin MA, Kluck HM, van der Heijden LH, Coebergh JWW (1993) Breast cancer in South-east Netherlands, 1960 1989: trends in incidence and mortality. Eur J Cancer 29A: 1557- 1560

Nattinger A, Gottlieb M, Veum J, Yahnke D, Goodwin J (1992) Geographic variation in the use of breast conserving treatment for breast cancer. $N$ Engl J Med 326: 1102-1107

Nattinger A, Hoffmana RG, Kneusel RT, Schapira MM (2000) Relation between appropriateness of primary therapy for early stage breast carcinoma and increased use of breast-conserving surgery. Lancet 356: $1148-1153$

Newlin ME, Reiling R, Nichols K (2002) Necessity of axillary dissection in elderly women with early breast cancer. World J Surg 26: 1239-1242

Poulsen B, Graversen HP, Beckmann J, Blichert-Toft M (1997) A comparative study of post-operative psychosocial function in women with primary operable breast cancer randomized to breast conservation therapy or mastectomy. Eur J Surg Oncol 23: 327-334

Pozo C, Carver CS, Noriega V, Harris SD, Robinson DS, Ketcham AS, Legaspi A, Moffat Jr FL, Clark KC (1992) Effects of mastectomy versus lumpectomy on emotional adjustment to breast cancer: a prospective study of the first year postsurgery. J Clin Oncol 10: 1292-1298

Ragaz J, Jackson SM, Le N, Plenderleith IH, Spinelli JJ, Basco VE, Wilson KS, Knowling MA, Coppin CM, Paradis M, Coldman AJ, Olivotto IA (1997) Adjuvant radiotherapy and chemotherapy in node-positive premenopausal women with breast cancer. $N$ Engl J Med 337: $956-962$

Recht A, Gray R, Davidson NE, Fowble BL, Solin LJ, Cummings FJ, Falkson G, Falkson HC, Taylor IV SG, Tormey DC (1999) Locoregional failure 10 years after mastectomy and adjuvant chemotherapy with or without tamoxifen without irradiation: experience of the Eastern Cooperative Oncology Group. J Clin Oncol 17: 1689-1700

Sainsbury R, Rider L, Smith A, MacAdam A, on behalf of the Yorkshire breast cancer group (1995) Does it matter where you live? Treatment variation for breast cancer in Yorkshire. Br J Cancer 71: 1275-1278

Schneider EC, Epstein AM, Malin JL, Kahn KL, Emanuel EJ (2004) Developing a system to assess the quality of cancer care: ASCO's national initiative on cancer care quality. J Clin Oncol 22: 2985-2991

Scorpiglione N, Nicolucci A, Grilli R, Angiolini C, Belfiglio M, Carinci F, Cubasso D, Filardo G, Labbrozi D, Mainini F, Mari E, Penna A, Zola P, 
Type of surgery and guideline adherence in breast cancer

$M$ Schaapveld et al

Liberati A (1995) Appropriateness and variation of surgical treatment of breast cancer in Italy: when excellence in clinical research does not match with generalized good quality care. J Clin Epidemiol 48: 345-352

Sobin LH, Wittekind C (eds) (1997) International Union Against Cancer (UICC): TNM Classification of Malignant Tumors, 5th edn. New York, Chichester, Weinheim, Brisbane, Singapore, Toronto: Wiley-Liss

Veronesi U, Saccozzi R, Del Vecchio M, Banfi A, Clemente C, De Lena M, Gallus G, Greco M, Luini A, Marubini E, Muscolino G, Rilke F, Salvadori B, Zecchini A, Zucali R (1981) Comparing radical MRM with quadrantectomy, axillary dissection and radiotherapy in patients with small cancers of the breast. N Engl J Med 305: 6-11

Voogd AC, van Beek MW, Crommelin MA, Kluck HM, Repelaer van Driel OJ, Coebergh JW (1994) Management of early breast cancer in southeast
Netherlands since 1984. A population-based study. Regional Breast Cancer Study Group. Acta Oncol 33: 753-757

Wazer DE, Erban JK, Robert NJ, Smith TJ, Marchant DJ, Schmid C, DiPetrillo T, Schmidt-Ullrich R (1994) Breast conservation in elderly women for clinically negative axillary lymph nodes without axillary dissection. Cancer 74: $878-883$

Whelan T, Levine M, Gafni A, Sanders K, Willan A, Mirsky D, Schnider D, McCready D, Reid S, Kobylecky A, Reed K (1999) Mastectomy or lumpectomy? Helping women make informed choices. J Clin Oncol 17: $1727-1735$

Whelan TJ, Julian J, Wright J, Jadad AR, Levine ML (2000) Does locoregional radiation therapy improve survival in breast cancer? A meta-analysis. J Clin Oncol 18: 1220-1229 